\title{
Co-culture with potentially probiotic microorganisms antagonises virulence factors of Clostridium difficile in vitro
}

\author{
Fernando M. Trejo • Pablo F. Pérez • \\ Graciela L. De Antoni
}

Received: 29 September 2009/Accepted: 3 March 2010/Published online: 16 March 2010

(C) Springer Science+Business Media B.V. 2010

\begin{abstract}
Toxigenic strains of Clostridium difficile were co-cultured with different strains of bifidobacteria and lactobacilli. Spent culture supernatants were tested for biological activity on cultured Vero cells. Co-culture of $C$. difficile with some potentially probiotic strains lead to a reduction of the biological activity of spent culture supernatants. The observed effects cannot be ascribed either to secreted factors from the probiotic strains or to toxin adsorption by bacterial cells. Immunological assays showed that there was significant diminution of both clostridial toxins (TcdA and TcdB) in spent culture supernatants of co-cultures as compared with pure clostridial cultures. Even though co-cultured clostridial cells showed a slight increase of intracellular toxins, this increase did not completely explains the reduction of toxin concentration in culture supernatants. The evidence suggests that the antagonism could be due to the diminution of the synthesis and/or secretion of
\end{abstract}

F. M. Trejo · P. F. Pérez $(\bowtie) \cdot$ G. L. De Antoni

CCT La Plata, CONICET, Centro de Investigación y

Desarrollo en Criotecnología de Alimentos (CIDCA),

Facultad de Ciencias Exactas, Universidad Nacional de La

Plata, 47 y 116 (1900), La Plata, Argentina

e-mail: pfp@biol.unlp.edu.ar

P. F. Pérez - G. L. De Antoni

Cátedra de Microbiología, Facultad de Ciencias Exactas,

Universidad Nacional de La Plata, La Plata, Argentina

G. L. De Antoni

CIC-PBA, Buenos Aires, Argentina both clostridial toxins. Our findings provide new insights into the possible mechanisms involved in the protective effect of probiotics in the context of $C$. difficile infection.

Keywords Bifidobacterium - Lactobacillus . Clostridium difficile · Probiotics · Toxins · Virulence

$\begin{array}{ll}\text { Abbreviations } \\ \text { SCS } & \text { Spent culture supernatants } \\ \text { TcdA } & \text { C. difficile toxin A } \\ \text { TcdB } & \text { C. difficile toxin B } \\ \text { CDAD } & \text { C. difficile associated diarrhea } \\ \text { OD } 600 \mathrm{~nm} & \text { Optical density at } 600 \mathrm{~nm} \\ \text { PBS } & \text { Phosphate buffered saline } \\ \text { DMEM } & \text { Dulbbeco's Modified Eagle's Medium } \\ \text { rd } & \text { Ratio of detached cells } \\ \text { NBT } & \text { Nitro-blue tetrazolium chloride } \\ \text { BCIP } & \text { 5-Bromo-4-chloro-3'-indolyphosphate } \\ & \text { p-toluidine salt } \\ \text { DD50 } & \begin{array}{l}\text { Dose of SCS that leads to the } \\ \text { detachment of 50\% of the cells }\end{array}\end{array}$

\section{Introduction}

Clostridium difficile is a Gram-positive spore forming bacterium that is carried asymptomatically in about $50 \%$ of neonates, $20 \%$ of hospitalized patients and $2 \%$ of healthy adults (Matsuki et al. 2005; Gursoy 
et al. 2007). In hospitalized individuals, administration of proton pump inhibitors or antibiotics such as clindamycin, cephalosporins, fluoroquinolones and ampicillin disturb the normal intestinal microbiota thus leading to the overgrowth of intestinal $C$. difficile or colonization with environmental clostridia that are normally present in healthcare centers (Schroeder 2005; Sunenshine and McDonald 2006; Dubberke et al. 2007). In this context, C. difficile is responsible for $90-100 \%$ of cases of pseudomembranous colitis (PMC), $60-75 \%$ of antibiotic-associated colitis and $30-60 \%$ of antibiotic-associated diarrhea (AAD) (Limaye et al. 2000). The main virulence factors of this microorganism are two large protein toxins: TcdA (308 kDa) and TcdB (260 kDa). These toxins act as glycosyltransferases that modify host cell small GTPases that are involved in actin polymerization and cytoskeleton assembly (Schirmer and Aktories 2004; Jank et al. 2007).

Evidence suggests that probiotics constitute an alternative approach to prevent/treat $C$. difficile associated diarrhea (CDAD). Indeed, there are several reports on the correction of microbiota unbalances by the administration of probiotics (Colombel et al. 1987; Wullt et al. 2003; Plummer et al. 2004; Kotowska et al. 2005; Segarra-Newnham 2007) or prebiotics (Lewis et al. 2005). Concerning mechanisms involved in the antagonism of $C$. difficile by probiotic microorganisms, evidence suggests that Saccharomyces boulardii could interfere with the virulence of $C$. difficile through different mechanisms such as toxin neutralization and inhibition of the inflammatory response (Chen et al. 2006). In addition, it has been demonstrated that pathogen adhesion to enterocyte-like cells and growth are significantly reduced by bifidobacterial extracellular factors (Trejo et al. 2006).

Given that the main virulence factors of $C$. difficile are TcdA and TcdB, we aimed to assess the effect of probiotic microorganisms on the production/secretion of these extracellular factors.

\section{Materials and methods}

Bacterial strains and growth conditions

Strains of bifidobacteria and lactobacilli included in the present study are shown in Table 1. Two strains
Table 1 Bifidobacterium and Lactobacillus strains used in the present study

\begin{tabular}{|c|c|c|}
\hline $\begin{array}{l}\text { Bifidobacterium and } \\
\text { Lactobacillus strains }\end{array}$ & Strain & References \\
\hline B. bifidum & $\operatorname{NCC} 235^{\mathrm{a} 1}$ & I \\
\hline B. bifidum & CIDCA $539^{2}$ & I \\
\hline B. bifidum & CIDCA $5310^{2}$ & I \\
\hline B. bifidum & CIDCA $5311^{2}$ & I \\
\hline B. bifidum & CIDCA $5313^{2}$ & I \\
\hline B. bifidum & CIDCA $5318^{2}$ & I \\
\hline B. breve & CIDCA $532^{1}$ & I \\
\hline B. breve & CIDCA $5312^{2}$ & I \\
\hline B. breve & CIDCA $5314^{2}$ & I \\
\hline B. breve & CIDCA $5315^{2}$ & I \\
\hline B. infantis & $\mathrm{NCC} 200^{\mathrm{b} 2}$ & I \\
\hline B. longum & CIDCA $5316^{2}$ & I \\
\hline B. longum & CIDCA $5320^{3}$ & I \\
\hline B. longum & CIDCA $5325^{4}$ & I \\
\hline B. longum & CIDCA $5323^{4}$ & I \\
\hline B. pseudolongum & CIDCA 531 & I \\
\hline B. adolescentis & CIDCA $5317^{1}$ & I \\
\hline Bifidobacterium spp. & CIDCA $5329^{2}$ & II \\
\hline L. acidophilus & $\operatorname{ATCC} 314^{c}$ & III \\
\hline L. brevis & ATCC $8287^{\mathrm{c}}$ & III \\
\hline L. casei & DSMZ $20011^{\mathrm{d}}$ & III \\
\hline L. kefir & CIDCA $8348^{\mathrm{e}}$ & III \\
\hline L. kefir & CIDCA $8321^{\mathrm{e}}$ & III \\
\hline L kefir & CIDCA $8344^{\mathrm{e}}$ & III \\
\hline L. plantarum & CIDCA $83114^{\mathrm{e}}$ & III \\
\hline
\end{tabular}

Strain CIDCA 531 was isolated from a fermented dairy product. Remaining strains were isolated from infant feces (aged from 6 days to 4 months)

Feeding: ${ }^{1}$ Formula + Brest, ${ }^{2}$ Breast, ${ }^{3}$ Formula, ${ }^{4}$ UHT milk

I: Gomez Zavaglia et al. 1998; Perez et al. 1998. II: Trejo et al. 2006. III: Garrote et al. 2001

a Nestlé Culture Collection. Formerly strain CIDCA 533

b Nestlé Culture Collection. Formerly strain CIDCA 538

c American Type Culture Collection

d DSMZ Deustche Smmlung von Mikroorganismen und Zellkulturen Gmbh, Germany

e Isolated from kefir grains

of $C$. difficile were studied: ATCC 9689 (Bélanger et al. 2003) and the clinical isolate 117. Both strains are positive for $\mathrm{Tcd} A$ and $\mathrm{TcdB}$. Clostridia were grown for $20 \mathrm{~h}$ at $37^{\circ} \mathrm{C}$ in Brain Heart Infusion (BHI: Biokar Diagnostic, Beauvais, France) supplemented with $0.05 \%(\mathrm{w} / \mathrm{v})$ cysteine chlorhydrate (BHI/cys) in 
anaerobic conditions (AnaeroPak, Mitshubishi Gas Chemical Co, Inc). Plate counts were performed by plating serial dilutions of the cultures on Differential Reinforced Clostridium Medium (DRCM; Laboratorios Britania S.A., Argentina). Plates were incubated for $72 \mathrm{~h}$ at $37^{\circ} \mathrm{C}$ in anaerobic conditions.

Bifidobacteria and lactobacilli were grown in MRS broth (DIFCO, Becton-Dickinson and Company Sparks, MD 21252, USA) supplemented with $0.05 \%$ (w/v) cysteine chlorhydrate at $37^{\circ} \mathrm{C}$ for $20 \mathrm{~h}$ in anaerobic conditions. Plate counts were performed by plating serial dilutions on MRS agar (DIFCO). Plates were incubated for $48 \mathrm{~h}$ at $37^{\circ} \mathrm{C}$ in anaerobic conditions.

\section{Co-cultures}

Five $\mathrm{ml}$ of BHI/cys were inoculated with $50 \mu \mathrm{l}$ of $20 \mathrm{~h}$ old Clostridium culture $\left(10^{8} \mathrm{CFU} \mathrm{ml}^{-1}\right)$ and $50 \mu \mathrm{l}$ of $20 \mathrm{~h}$ old Bifidobacterium $\left(5 \times 10^{8}\right.$ $\left.\mathrm{CFU} \mathrm{ml} \mathrm{m}^{-1}\right)$ or Lactobacillus $\left(5 \times 10^{8} \mathrm{CFU} \mathrm{m}{ }^{-1}\right)$ cultures. Co-cultures were incubated for $20 \mathrm{~h}$ at $37^{\circ} \mathrm{C}$ in anaerobic conditions. Spent culture supernatants were obtained by centrifugation at $13600 \times g$ for 15 min. Biological activity of co-cultures was compared with pure Clostridium cultures as described below.

\section{Cell cultures}

Vero cells were grown in Dulbecco's Modified Eagle's Medium (DMEM; Gibco BRL Life Technologies, Rockville, MD, USA) supplemented with $10 \%$ $(\mathrm{v} / \mathrm{v})$ inactivated $\left(30 \mathrm{~min} / 60^{\circ} \mathrm{C}\right)$ fetal calf serum (BIOSER, Argentina, PAA Laboratories $\mathrm{GmbH}$ ), $2 \mathrm{~g} \mathrm{l}^{-1} \mathrm{NaHCO}_{3}, \quad 10 \mathrm{mg} \mathrm{l}^{-1}$ streptomycin and $10 \mathrm{IU} \mathrm{ml}^{-1}$ penicillin $\mathrm{G}$. Cells were inoculated $\left(7.5 \times 10^{4}\right.$ cells per well) into 48 -well tissue culture plates (Corning, NY) and incubated at $37^{\circ} \mathrm{C}$ for $48 \mathrm{~h}$ in a $5 \%(\mathrm{v} / \mathrm{v}) \mathrm{CO}_{2}-95 \%(\mathrm{v} / \mathrm{v})$ air atmosphere.

\section{Biological effects on cultured cells}

Cultured cells were washed twice with $1 \mathrm{ml}$ of phosphate buffered saline (PBS; $\mathrm{KH}_{2} \mathrm{PO}_{4} 0.144 \mathrm{~g} \mathrm{l}^{-1}$, $\mathrm{NaCl} 9 \mathrm{~g} \mathrm{l}^{-1}, \mathrm{Na}_{2} \mathrm{HPO}_{4} 0.795 \mathrm{~g} \mathrm{l}^{-1}, \mathrm{pH}$ 7.5). Spent culture supernatants (SCS) were serially (two fold) diluted in DMEM without fetal calf serum. One hundred $\mu \mathrm{l}$ of diluted SCS were added per well and incubated at $37^{\circ} \mathrm{C}$ for $16 \mathrm{~h}$ in a $5 \% \mathrm{CO}_{2} / 95 \%$ air atmosphere. Biological activity was assessed by determination of cell rounding, labeling of F-actin cytoskeleton and evaluation of cell detachment (Minnaard et al. 2001, 2004)).

Cell rounding was evaluated by microscopy and the dose of SCS that leads to the rounding of $50 \%$ of the cells (Dr50) was determined. Staining of F-actin cytoskeleton was performed according to Minnaard et al. (2004). Briefly, Vero cells were grown on sterile glass coverslips (Assistant, Sondheim, Germany) in 24-well culture plates (Greiner Bio One, Germany). After incubation with SCS, cells were washed twice with PBS, fixed (2 min) with $3 \%$ (v/v) paraformaldehyde and washed again with PBS. Next, cells were treated with $\mathrm{NH}_{4} \mathrm{Cl}(50 \mathrm{mM})$ and then permeabilized with $0.2 \%(\mathrm{v} / \mathrm{v})$ Triton $\times 100$ solution in PBS. Cells were washed with PBS and then labeled with FITCphalloidin (SIGMA, Inc., St. Louis, MO, USA) in PBS containing $0.2 \%$ (v/v) gelatin (SIGMA, Inc. St. Louis, MO, USA) for $45 \mathrm{~min}$ in the dark. Cells were observed by fluorescence microscopy.

To assay cellular detachment, after incubation with SCS, cells were washed twice with PBS and fixed with $2 \%(\mathrm{v} / \mathrm{v})$ formaldehyde for $1 \mathrm{~min}$ (Minnaard et al. 2001). The remaining cells were stained with $0.013 \%$ (w/v) Crystal Violet in 5\% (v/v) ethanol and 2\% (v/v) formaldehyde. Next, an extraction with $50 \%(\mathrm{v} / \mathrm{v})$ ethanol was performed and $\mathrm{OD}_{540}$ was determined. Biological activity was expressed as the ratio of detached cells (rd), according to the following expression:

$\mathrm{rd}=100 *\left(1-\left(\mathrm{ODs}-\mathrm{OD}_{0}\right) /\left(\mathrm{ODc}-\mathrm{OD}_{0}\right)\right)$

where ODs, optical density of sample; $\mathrm{OD}_{0}$, optical density of well without cells (control of stain adsorption by the well); ODc, optical density of untreated control cells.

The ratio of detached cells (rd) was modeled as a function of SCS concentration by using the following hyperbolic function:

$\mathrm{rd}=\mathrm{aC} /(\mathrm{b}+\mathrm{C})$,

where $\mathrm{C}$ is the concentration (\% v/v) of SCS; $\mathrm{a}$ and $\mathrm{b}$ are parameters of the equation. By means of this model, the dose of SCS that leads to the detachment of $50 \%$ of the cells (DD50) can be calculated. This parameter is useful to compare biological effects of different SCS since DD50 inversely correlates with biological activity. 
Effect of extracellular factors from bifidobacteria and lactobacilli

Two series of experiments were conducted. Firstly, cytotoxicity assays were performed with different ratios of SCS (Clostridium/Bifidobacterium or Lactobacillus). Ratios (volume of Clostridium SCS/ volume of Lactobacillus of Bifidobacterium SCS) tested were 0.5:1, 1:1 and 2:1. Secondly, Clostridium strains were grown in the presence of different concentration $(25 \%$ and $50 \% \mathrm{v} / \mathrm{v})$ of Bifidobacterium or Lactobacillus SCS. Afterwards, cytotoxicity assays were conducted as described above.

Determination of extracellular toxin concentration in spent culture supernatants

Bacterial cultures were centrifuged at $13600 \times g$ for $15 \mathrm{~min}$ and $2 \mu \mathrm{l}$ of supernatants were spotted onto nitrocellulose membranes. Blocking was performed with $3 \%(\mathrm{w} / \mathrm{v})$ skim milk in buffer TRIS/Tween: TRIS $50 \mathrm{mM}$ (Hydroymethyl aminomethane Mallinckrodt, Baker Inc.), $\mathrm{NaCl} 150$ mM pH 7.5, Tween
20 (Sigma-Aldrich, Inc., St. Louis, MO, USA) $0.05 \%$. Afterwards, membranes were incubated for $40 \mathrm{~min}$ at $37^{\circ} \mathrm{C}$ with mouse anti-TcdA or anti-TcdB monoclonal antibodies (Meridian Life Science, Unc.). Next, membranes were incubated with biotin-goat anti mouse IgG and extravidin-alkaline phosphatase (Sigma-Aldrich, St. Louis, MO, USA). Finally, membranes were treated with a solution of NBT/BCIP (Sigma-Aldrich, St. Louis, MO, USA) until color development. After each incubation step, membranes were exhaustively washed with buffer TRIS/Tween. Toxin concentration was calculated by image analysis (TotalLab v2.01, Pharmacia, Orsay, France) and referred to that produced in pure cultures. Two independent assays were performed.

\section{Determination of intracellular toxin concentration}

One $\mathrm{ml}$ of bacterial culture (pure Clostridium or cocultures) containing $10^{8} \mathrm{CFU} \mathrm{ml}{ }^{-1} \mathrm{C}$. difficile was centrifuged at $14000 \times g$ for $5 \mathrm{~min}$ and washed twice with PBS. Afterwards, the pellet was suspended in $1 \mathrm{ml}$ of PBS and 5 pulses of sonication (6 min each)
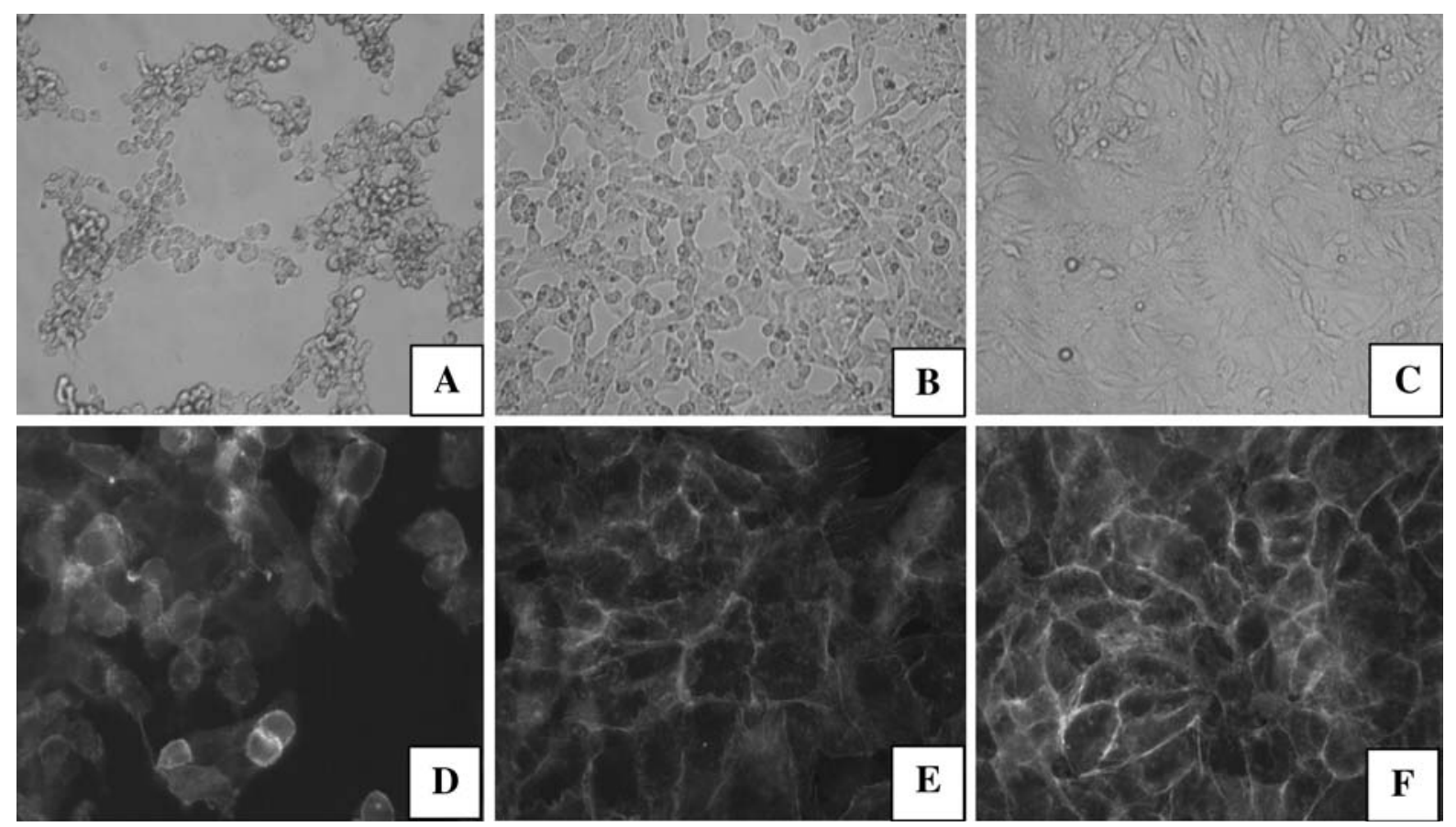

Fig. 1 Effect on Vero cells of SCS from pure cultures of $C$. difficile or co-cultures with Bifidobacterium bifidum 5310. SCS were diluted in DMEM $1 / 16$ a pure culture of $C$. difficile ATCC 9689, b co-culture of $C$. difficile and B. bifidum 5310, c control cells, d pure culture of $C$. difficile ATCC 9689, F-actin labeling, e co-culture of $C$. difficile and B. bifidum 5310, Factin labeling and $\mathbf{f}$ control cells, F-actin labeling 
were performed $(20 \mathrm{kc}, \mathrm{c}: 1 / \mathrm{s}$, Ultrasonic Disintegrator, Model 60w, MSE Ltd.). Cell disruption was checked microscopically. After sonication, samples were centrifuged at $13600 \times g$ for $15 \mathrm{~min}$ and $2 \mu \mathrm{l}$ of supernatants were spotted onto nitrocellulose membranes. Toxin detection was conducted as indicated above.

\section{Statistical analysis}

Results were analysed by means of two-tailed Student's $t$ test using the InfoStat software (InfoStat, Version 2008, Grupo InfoStat, FCA, Universidad Nacional de Córdoba, Argentina). To assess the effects on toxin concentrations, the null hypothesis that toxin concentration in the co-cultures and toxin concentration of pure clostridial cultures were equal was tested.

\section{Results \\ Cytopathic effects}

Spent culture supernatants (SCS) of C. difficile ATCC 9689 lead to profound effects on cultured eukaryotic cells. As shown in Fig. 1, cytopathic effects encompass disorganization of the actin network that in turn leads to cell rounding and detachment (Fig. 1a, d). In contrast, when the same clostridial strain was co-cultured with Bifidobacterium bifidum strain CIDCA 5310, cytopathic effects were significantly diminished (Fig. 1b, e). Untreated control cells are shown in Fig. 1c and f.

Screening of the ability of several bifidobacteria and lactobacilli to antagonize cytopathic effects of C. difficile was performed by assessing the dose of SCS that leads to the rounding of $50 \%$ of the cells (Dr50) (Fig. 2). This allowed for the selection of strains able to antagonize cytopathic effects associated with $C$. difficile extracellular factors. High Dr50 indicates low biological activity. As shown in Fig. 2, the ability to antagonize cytopathic effects was straindependent. Interestingly, some strains (e.g. CIDCA 531, CIDCA 532, CIDCA 5310, ATCC 8287 and CIDCA 83114) were able to inhibit cytopathic effects from both clostridial strains under study.

On the basis of their ability to antagonize biological activity of both clostridial strains, B. bifidum
CIDCA 5310 and Lactobacillus plantarum CIDCA 83114 were selected for further studies. Noteworthy, no inhibition of the growth of $C$. difficile was observed in co-cultures with strains CIDCA 5310 or CIDCA 83114 (Table 2A). In addition, growth of lactobacilli and bifidobacteria was not affected by the presence of clostridia in co-cultures (Table 2B).

Cellular detachment

Biological activity, expressed as the ratio of detached cells (rd), was modeled as a function of SCS concentration and DD50 was calculated as indicated
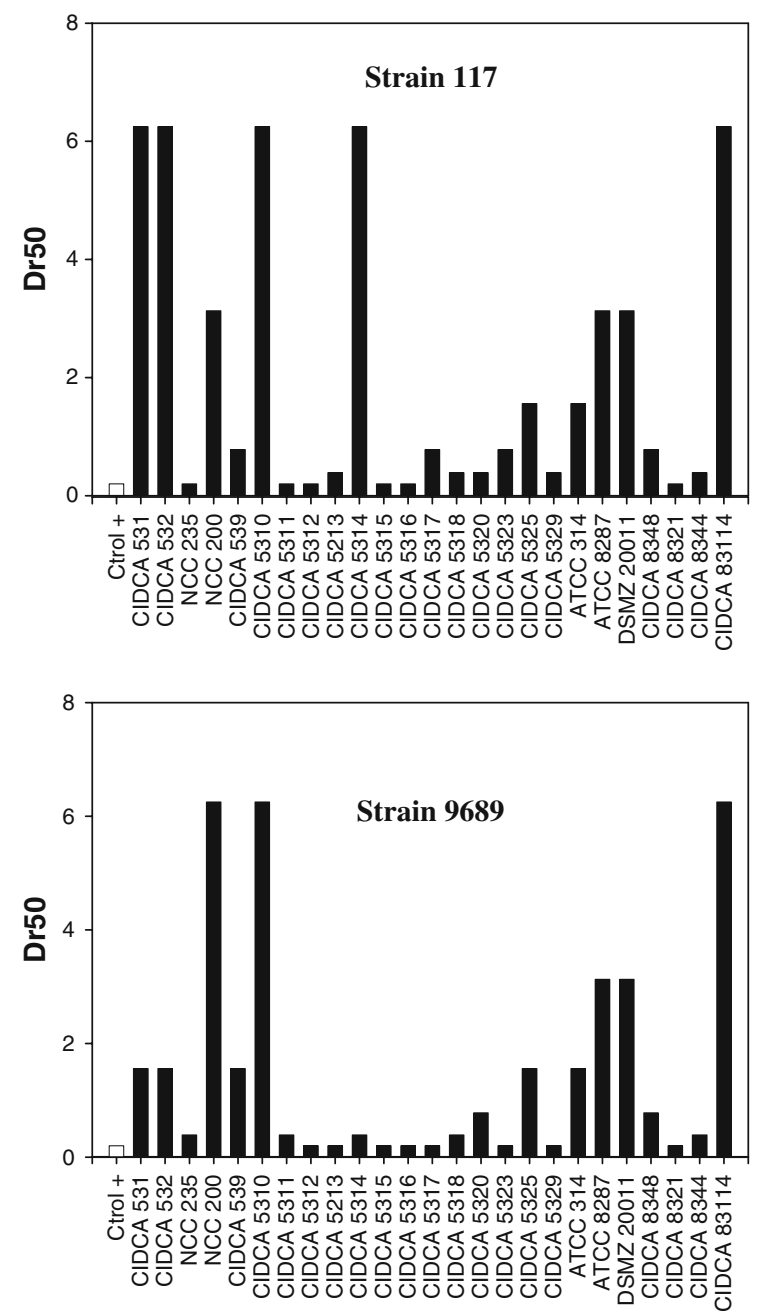

Fig. 2 Effect of co-culture of clostridia with bifidobacteria or lactobacilli on the biological activity of SCS on Vero cells. Results are expressed as the dose that leads to the rounding or $50 \%$ of the cells (Dr50). Pure culture (open square); co-culture with Bifidobacterium or Lactobacillus strains (filled square) 
Table 2 (A) Growth of $C$. difficile in pure cultures and in co-cultures with B. bifidum strain CIDCA 5310 or L. plantarum strain CIDCA 83114; (B) Growth of B. bifidum strain CIDCA 5310 or L. plantarum strain CIDCA 83114 in pure cultures and in co-cultures with $C$ difficile strains

\begin{tabular}{|c|c|c|c|}
\hline A & Pure culture $\left(\log \mathrm{CFU} \mathrm{ml} \mathrm{m}^{-1}\right)$ & $\begin{array}{l}\text { Co-culture with B. bifidum } \\
5310\left(\log \text { CFU ml }{ }^{-1}\right)\end{array}$ & $\begin{array}{l}\text { Co-culture with L. plantarum } \\
83114\left(\log \text { CFU ml }{ }^{-1}\right)\end{array}$ \\
\hline C. difficile strain 117 & $8.32 \pm 0.03(\mathrm{pH} 6.41 \pm 0.12)$ & $8.21 \pm 0.03(\mathrm{pH} 6.19 \pm 0.12)$ & $7.80 \pm 0.11(\mathrm{pH} 6.09 \pm 0.10)$ \\
\hline C. difficile strain 9689 & $7.83 \pm 0.04(\mathrm{pH} 6.61 \pm 0.12)$ & $7.73 \pm 0.02(\mathrm{pH} 6.36 \pm 0.18)$ & $7.50 \pm 0.20(\mathrm{pH} 6.16 \pm 0.13)$ \\
\hline B & Pure culture $\left(\log \mathrm{CFU} \mathrm{ml} \mathrm{m}^{-1}\right)$ & $\begin{array}{l}\text { Co-culture with } C . \text { difficile } \\
117\left(\log \mathrm{CFU} \mathrm{ml} \mathrm{m}^{-1}\right)\end{array}$ & $\begin{array}{l}\text { Co-culture with } C \text {. difficile } \\
9689\left(\log \mathrm{CFU} \mathrm{ml}{ }^{-1}\right)\end{array}$ \\
\hline Bifidobacterium strain 5310 & $8.20 \pm 0.20$ & $7.79 * \pm 0.20$ & $8.31 \pm 0.50$ \\
\hline Lactobacillus 83114 & $8.66 \pm 0.30$ & $8.49 \pm 0.20$ & $8.18 \pm 0.50$ \\
\hline
\end{tabular}

In brackets, $\mathrm{pH} \pm$ standard deviation of cultures or co-cultures are indicated

* Significantly different from pure culture. Student $t$ test $(P<0.05)$

in the "Material and Methods" section (Fig. 3). Interestingly, when biological activity of SCS from co-cultures were analysed, DD50 values were from 5 to 20 times higher than those from pure clostridial cultures (Fig. 4).

Effect of extracellular factors from

Bifidobacterium and Lactobacillus cultures on the biological activity of $C$. difficile

Dilution of clostridial SCS with lactobacilli or bifidobacteria SCS did not antagonise the biological effects of strain 117 (Table 3). In contrast, biological activity of strain 9689 was not modified by SCS from Lactobacillus strain 83114 but a significant decrease of activity was observed when SCS from Bifidobacterium strain 5310 was used (Table 3 ). In addition, growth of clostridial strains in BHI medium with different concentrations of SCS from bifidobacteria or lactobacilli cultures did not abrogate the cytopathic effect (Table 3). Preincubation of clostridial SCS with high concentrations of either bifidobacteria or lactobacilli $\left(\mathrm{OD}_{600}=2\right)$ did not modify the biological activity (data not shown). It is worth noting that $20 \mathrm{~h}$ old cultures of bifidobacteria or lactobacilli in BHI broth do not acidify below pH 6 (data not shown), suggesting that change in $\mathrm{pH}$ is not responsible for biological effects.

\section{Determination of toxin concentration}

The above results prompted us to determine whether the diminution of the biological activity of SCS from co-cultures was due to the inhibition of toxin synthesis/activity or to the inhibition of toxin release from bacteria. To this end, we evaluated toxin concentration by immunoblotting (Fig. 5).

As shown in Fig. 6, TcdA concentration was dramatically reduced in co-cultures. Indeed, TcdA co-culture/TcdA pure culture ratios ranged from 0.1 to 0.3 (Fig. 6a) whereas TcdB co-cultures/TcdB pure culture ratios ranged from 0.1 to 0.5 (Fig. $6 \mathrm{~b}$ ).

The concentrations of the intracellular toxins of $C$. difficile strain 9689 were significantly lower when this strain was co-cultured with $B$. bifidum CIDCA 5310 (Table 4). There was a slight increase of intracellular TcdB of strain 117 when it was co-cultured with strain 5310 .

\section{Discussion}

Virulence of $C$. difficile is related to the production of two large (308-260 kDa) protein toxins: TcdA and TcdB. These extracellular factors have separate binding and enzymatic domains. The enzymatic domain is responsible for the glycosylation of proteins crucial for cytoskeleton assembly (i.e. Rho proteins). Even though both toxins have the same enzymatic activity, TcdA is mainly an enterotoxin whereas TcdB has cytotoxic activity (Lyerly et al. 1988). In vivo, the effect of these toxins leads to the recruitment of blood cells to the site of infection thus triggering a strong inflammatory response that is responsible for the clinical symptoms. It is known 

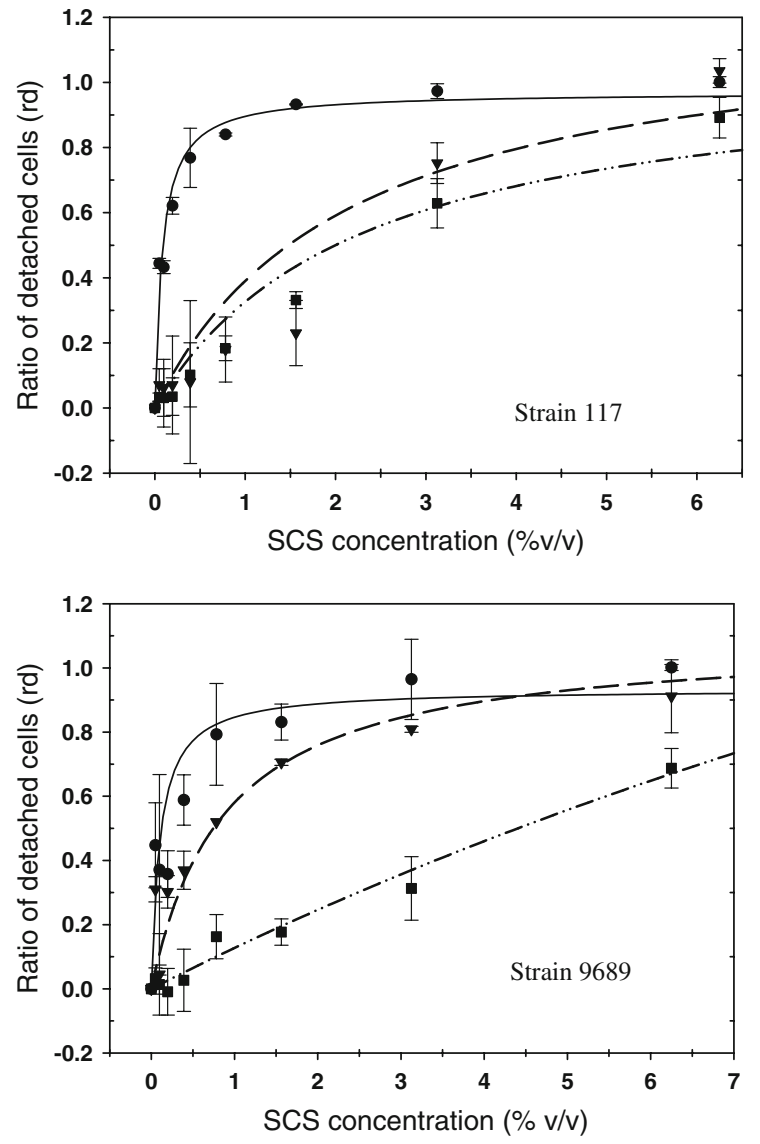

Fig. 3 Dose response curves of the biological activity of SCS. Results of biological activity are expressed as the ratio of detached cells (rd). (filled circle) pure culture of $C$. difficile, (filled square) co-culture of $C$. difficile and B. bifidum 5310, (filled inverted triangle) co-culture of $C$. difficile and L. plantarum 83114 . Results were adjusted to a hyperbolic model: $\mathrm{rd}=\mathrm{aC} /(\mathrm{b}+\mathrm{C})$, where rd: Ratio of detached cells and C: SCS concentration $(\% \mathrm{v} / \mathrm{v})$. A representative experiment from three independent assays is shown

that TcdB exerts its biological effect at lower doses than TcdA (Castagliuolo et al. 1998).

In the present study we show that growth of C. difficile in the presence of some strains of bifidobacteria or lactobacilli leads to SCS with significantly lower biological activity as compared with pure clostridial cultures.

Antagonism of intestinal pathogens by potentially probiotic microorganisms has long been ascribed to growth inhibition (Trejo et al. 2006; Rönnqvist et al. 2007), competitive exclusion (Collado et al. 2005; Ruas-Madiedo et al. 2006) or immunomodulation (Benyacoub et al. 2005; Humen et al. 2005; Niers

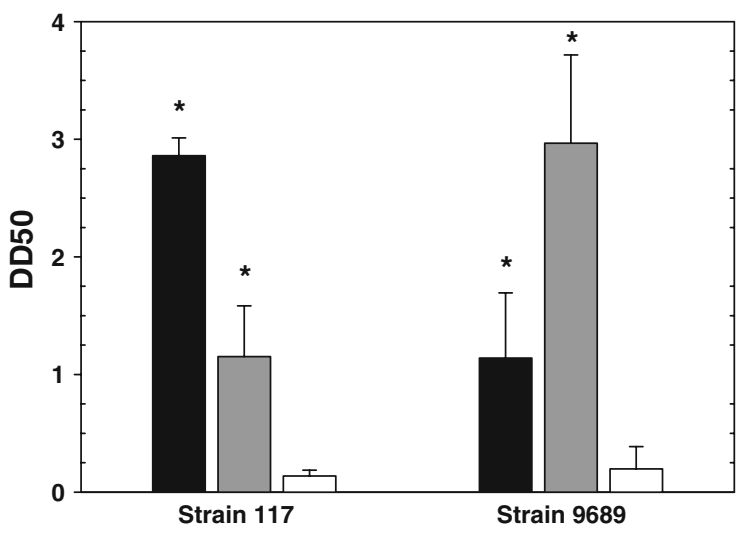

Fig. 4 Biological activity (DD50) of pure cultures of $C$. difficile (white bars) or co-cultures with B. bifidum strain 5310 (black bars) or L. plantarum 83114 (grey bars). Asterisks indicate significant differences $(P<0.01)$ from the control (pure culture of $C$. difficile). Results are expressed as means \pm standard deviation from three independent experiments

et al. 2007). Recently, novel mechanisms have been proposed. Indeed, inhibition of biological effect of Bacillus cereus by the polysaccharide kefiran (Medrano et al. 2008, 2009) and antagonism of virulence factors of enterohaemorrhagic Escherichia coli by probiotic lactobacilli have been demonstrated (Hugo et al. 2008).

Interestingly, the inhibition of the biological activity of $C$. difficile when co-cultured with lactobacilli has been reported (Banerjee et al.; 2009). In contrast with our observations, these authors suggest that SCS of lactobacilli contains some secreted factors that abolished biological activity of the Clostridium SCS. They hypothesize that proteolytic activity in the SCS would lead to toxin cleavage thus modifying biological activity. This hypothesis is in agreement with published results on the effect of $S$. boulardii on the activity of clostridial toxins (Castagliuolo et al. 1998).

Even though in the above-mentioned studies protective effects were clearly shown, the underlying mechanisms have not yet been elucidated. The present study gives further insight on the possible mechanisms involved. Indeed, we show that production of $C$. difficile toxins is significantly diminished in co-cultures. In addition, a slight effect on the toxin release was observed. Notably, growth of clostridial strains in co-cultures was similar to pure clostridial control cultures.

Toxin production by $C$. difficile is influenced by environmental conditions such as growth phase 
Table 3 Biological activity (DD50 ${ }^{\mathrm{a}}$ ) of spent culture supernatants from $C$. difficile in different experimental conditions

\begin{tabular}{|c|c|c|c|c|c|c|}
\hline \multirow[t]{3}{*}{ C. difficile strain } & \multirow{3}{*}{$\begin{array}{l}\text { C. difficile } \\
\text { pure culture }\end{array}$} & \multicolumn{5}{|l|}{ DD50 } \\
\hline & & \multicolumn{3}{|c|}{ Ratio $^{\text {b }} \mathrm{SCS}_{\mathrm{Cd}} / \mathrm{SCS}_{\mathrm{Lp}}$} & \multicolumn{2}{|c|}{$\begin{array}{l}\text { Percentage }^{c}(\mathrm{v} / \mathrm{v}) \text { of } \mathrm{SCS}_{\mathrm{Lp}} \\
\text { added to the culture medium }\end{array}$} \\
\hline & & $0.5: 1$ & $1: 1$ & $2: 1$ & 25.0 & 50.0 \\
\hline 117 & $0.11 \pm 0.06$ & $0.13 \pm 0.05$ & $0.13 \pm 0.01$ & $0.15 \pm 0.03$ & $0.17 \pm 0.09$ & $0.17 \pm 0.06$ \\
\hline 9689 & $0.24 \pm 0.21$ & $0.19 \pm 0.07$ & $0.11 \pm 0.05$ & $0.12 \pm 0.07$ & $0.13 \pm 0.17$ & $0.08 \pm 0.09$ \\
\hline \multirow[t]{3}{*}{ C. difficile strain } & \multirow{3}{*}{$\begin{array}{l}\text { C. difficile } \\
\text { pure culture }\end{array}$} & \multicolumn{5}{|l|}{ DD50 } \\
\hline & & \multicolumn{3}{|c|}{ Ratio $^{\mathrm{b}} \mathrm{SCS}_{\mathrm{Cd}} / \mathrm{SCS}_{\mathrm{Bb}}$} & \multicolumn{2}{|c|}{$\begin{array}{l}\text { Percentage }^{\mathrm{c}}(\mathrm{v} / \mathrm{v}) \text { of } \mathrm{SCS}_{\mathrm{Bb}} \\
\text { added to the culture medium }\end{array}$} \\
\hline & & $0.5: 1$ & $1: 1$ & $2: 1$ & 25.0 & 50.0 \\
\hline 117 & $0.11 \pm 0.06$ & $0.26 \pm 0.22$ & $0.19 \pm 0.09$ & $0.13 \pm 0.03$ & $0.07 \pm 0.02$ & $0.40 \pm 0.40$ \\
\hline 9689 & $0.24 \pm 0.21$ & $0.02 \pm 0.01$ & $0.02 \pm 0.01$ & $0.03 \pm 0.03$ & ND & ND \\
\hline
\end{tabular}

$S C S_{C d}$ SCS of pure culture of $C$. difficile, $S C S_{B b}$ SCS of pure culture of B. bifidum strain 5310, $S C S_{C d}$ SCS of pure culture of L. plantarum strain $83114, N D$ not determinated

${ }^{\text {a }}$ Dose of SCS that leads to $50 \%$ of cell detachment

b SCS of pure cultures of clostridia, bifidobacterias or lactobacilli were added to the cells at the indicated ratios

c Clostridia were cultured in BHI containing different percentages of SCS from bifidobacteria or lactobacilli cultures

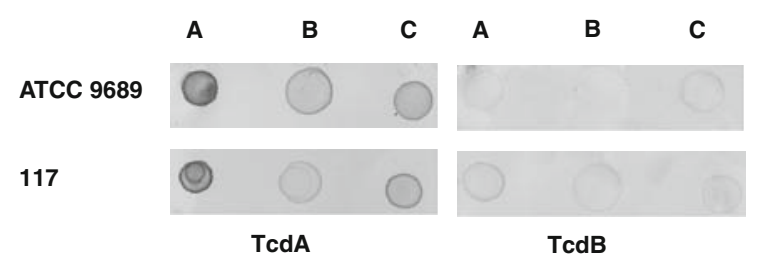

Fig. 5 Blots for TcdA and TcdB present in SCS. (A) $C$. difficile pure culture, $(B)$ Co-culture with B. bifidum strain 5310, (C) Co culture with L. plantarum strain 83114

(Hundsberger et al. 1997; Dupuy and Sonenshein 1998), aminoacids (Osgood et al. 1993), butyric acid (Karlsson et al. 2000), rapidly metabolizable carbon sources (Dupuy and Sonenshein 1998), antibiotics (Nakamura et al. 1982) and biotin (Yamakawa et al. 1998; Maegawa et al. 2002). Karlsson et al. (2008) demonstrated that during maximum toxin expression there is an increase of the enzymes involved in metabolic pathways related to succinate, folate and butyrate. Our findings demonstrate that co-culture with Bifidobacterium or Lactobacillus is able to inhibit biological activity of $C$. difficile. It can be hypothesized that during co-cultures, competition for nutrients would modify toxin production.

Genes related to $C$. difficile virulence are part of a pathogenicity locus positively regulated by an alternative sigma factor (TxeR) and negatively regulated by a membrane-associated protein encoded by the $t c d C$ gene (Mani and Dupuy 2001; Govind et al. 2006; Dineen et al. 2007). The $t c d E$ gene, coding for a holin that is involved in toxin release, is situated downstream of the $t c d B$ gene. Expression of both $t c d C$ and $t c d E$ are under the control of the same promoter. Taking into account that nutrient-sensing regulators control the expression of toxins in $C$. difficile (Dineen et al. 2007), we hypothesize that co-culture of clostridia with lactobacilli or bifidobacteria leads to the modification of the environment thus leading to the repression of toxin synthesis/secretion perhaps through quorum sensing mechanisms.

Taken together, our results suggest that co-culture of toxigenic $C$. difficile with selected probiotic microorganisms lead to a modification of the $C$. difficile microenvironment that in turns modifies signaling pathways related to toxin production. This property was not due to the inhibition of the pathogen growth. Presence of viable probiotic microorganisms rather than their products of secretion was necessary for the inhibitory effect. In addition, given the low proteolytic activity of both bifidobacteria and lactobacilli strains under study, the effect cannot readily be ascribed to toxin degradation. 

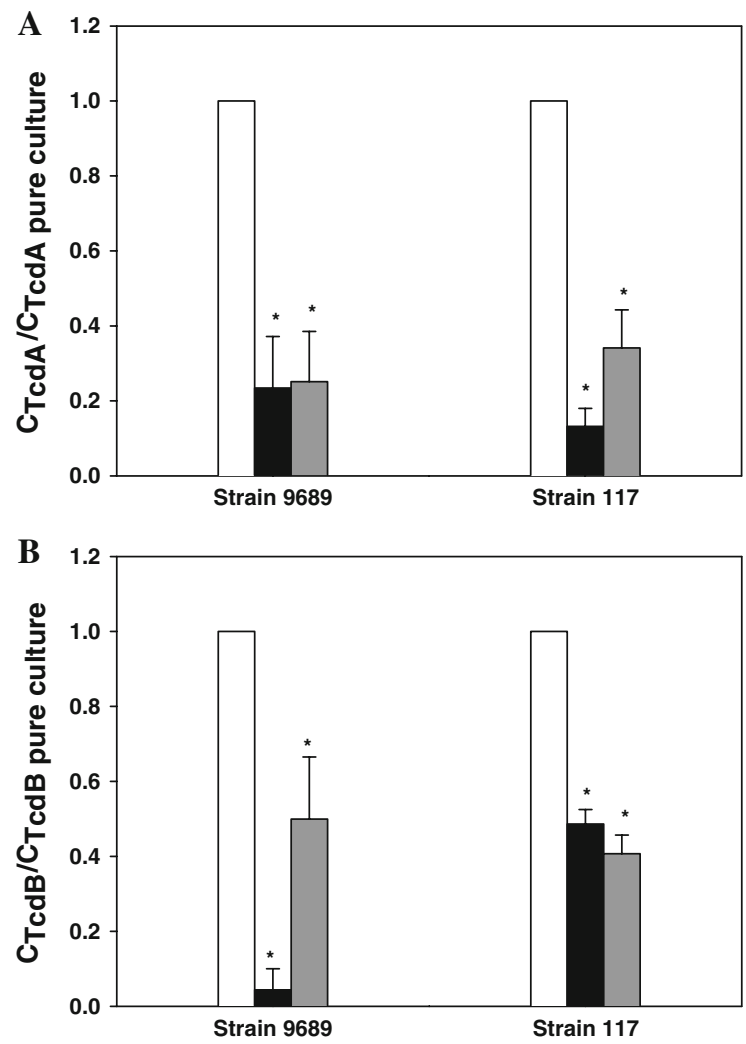

Fig. 6 Toxin (TcdA and TcdB) concentrations in spent culture supernatants. Results represent the ratio between spot intensity of co-cultures and pure clostridial cultures. Pure clostridial culture (white bars), co-culture with B. bifidum strain 5310 (black bars), co-culture with L. plantarum strain 83114 (grey bars). Results are expressed as means \pm standard deviation from three independent experiments

The results presented here provide evidence for novel protection mechanisms of probiotic microorganisms against intestinal pathogens. These results should contribute to understanding the mechanisms behind the protective effect of probiotics against C. difficile.

\section{References}

Banerjee P, Merkel GJ, Bhunia AK (2009) Lactobacillus delbrueckii ssp. bulgaricus B-30892 can inhibit cytotoxic effects and adhesion of pathogenic Clostridium difficile to Caco-2 cells. Gut Pathog 1:8-19

Bélanger SD, Boissinot M, Clairoux N, Picard FJ, Bergeron MG (2003) Rapid detection of Clostridium difficile in feces by Real-time PCR. J Clin Microbiol 41:730-734

Benyacoub J, Pérez PF, Rochat F, Saudan KY, Reuteler G, Antille LN, Humen MA, De Antoni GL, Cavadini C, Blum S, Schiffrin EJ (2005) Enterococcus faecium strain SF68 improves immune response to Giardia intestinalis in mice. J Nutr 135:1171-1176

Castagliuolo I, Keates AC, Wang CC, Pasha A, Valenick L, Kelly CP, Nikulasson ST, LaMont JT, Pothoulakis C (1998) Clostridium difficile toxin A stimulates macrophage-inflammatory protein-2 production in rat intestinal epithelial cells. J Immunol 160:6039-6045

Chen X, Kokkotou EG, Mustafa N, Bhaskar KR, Sougioultzis S, Pothoulakis C, Kelly CP (2006) Saccharomyces boulardii inhibits ERK1/2 mitogen activated protein kinase activation both in vitro and in vivo and protects against Clostridium difficile toxin A-induced enteritis. J Biol Chem 281:24449-24454

Collado MC, Gueimonde M, Hernández M, Sanz Y, Salminen S (2005) Adhesion of selected Bifidobacterium strains to human intestinal mucus and the role of adhesion in enteropathogen exclusion. J Food Prot 68:2672-2678

Colombel JF, Cortot A, Neut C, Romond C (1987) Yoghurt with Bifidobacterium longum reduces erythromycininduced gastrointestinal effects. Lancet 2:43

Dineen SS, Villapakkam AC, Nordman JT, Sonenshein AL (2007) Repression of Clostridium difficile gene expression by CodY. Mol Microbiol 66:206-219

Dubberke ER, Reske KA, Yan Y, Olsen MA, McDonald LC, Fraser VJ (2007) Clostridium difficile-associated disease in a setting of endemicity: identification of novel risk factors. Clin Infect Dis 45:1543-1549

Table 4 Levels of intracellular TcdA and TcdB produced in pure culture of $C$. difficile or co-cultures with bifidobacteria or lactobacilli

\begin{tabular}{|c|c|c|c|c|c|c|}
\hline \multirow[t]{2}{*}{ C. difficile strain } & \multicolumn{2}{|l|}{ Pure culture } & \multicolumn{2}{|c|}{$\begin{array}{l}\text { Co-culture with } B \text {. bifidum } \\
\text { strain } 5310\end{array}$} & \multicolumn{2}{|c|}{$\begin{array}{l}\text { Co-culture with } \\
\text { L. plantarum } \\
\text { strain } 83114\end{array}$} \\
\hline & TcdA & TcdB & TcdA & TcdB & TcdA & TcdB \\
\hline 117 & $1.01 \pm 0.33$ & $1.05 \pm 0.02$ & $3.05 \pm 2.01$ & $3.03 * \pm 0.31$ & $3.01 \pm 1.01$ & $1.11 \pm 0.91$ \\
\hline 9689 & $1.03 \pm 0.21$ & $1.01 \pm 0.01$ & $0.10 * \pm 0.05$ & $0.11 * \pm 0.06$ & $0.61 \pm 0.30$ & $1.15 \pm 0.87$ \\
\hline
\end{tabular}

Values are expressed as the ratio between spot intensity from co-cultures and pure cultures

* Significant differences $(P<0.05)$ from the theoretical ratio $=1$ 
Dupuy B, Sonenshein AL (1998) Regulated transcription of Clostridium difficile toxin genes. Mol Microbiol 27: 107-120

Garrote GL, Abraham AG, De Antoni AG (2001) Chemical and microbiological characterisation of kefir grains. J Dairy Res 68:639-652

Gomez Zavaglia A, Kociubinski G, Pérez PF, De Antoni GL (1998) Isolation and characterization of Bifidobacterium strains for probiotic formulation. J Food Prot 61:865-873

Govind R, Vediyappan G, Rolfe RD, Fralik JA (2006) Evidence that Clostridium difficile $\mathrm{TcdC}$ is a membraneassociated protein. J Bacteriol 188:3716-3720

Gursoy S, Guven K, Arikan T, Yurci A, Torun E, Baskol M, Ozbakir O, Yucesoy M (2007) Clostridium difficile infection frequency in patients with nosocomial infections or using antibiotics. Hepatogastroenterology 54:17201724

Hugo AA, Kakisu EJ, De Antoni GL, Pérez PF (2008) Lactobacilli antagonize biological effects of enterohaemorrhagic Escherichia coli in vitro. Lett Appl Microbiol 46:613-619

Humen MA, De Antoni GL, Benyacoub J, Costas ME, Cardozo MI, Kozubsky L, Saudan K-Y, Boenzli-Bruand A, Blum S, Schiffrin EJ, Pérez PF (2005) Lactobacillus johnsonii La1 antagonizes Giardia intestinalis in vivo. Infect Immun 73:1265-1269

Hundsberger T, Braun V, Weidmann M, Leukel P, Sauerborn M, Von Eichel-Streiber C (1997) Transcription analysis or the genes tcdA-E of the pathogenicity locus of Clostridium difficile. Eur J Biochem 244:735-742

Jank T, Giesemann T, Aktories K (2007) Rho-glucosylating Clostridium difficile toxins $\mathrm{A}$ and $\mathrm{B}$ : new insights into structure and function. Glycobiology 17:15R-22R

Karlsson S, Lindberg A, Norin E, Burman LG, Akerlund T (2000) Toxins, butyric acid, and short-chain fatty acids are coordinately expressed and down-regulated by cysteine in Clostridium difficile. Infect Immun 68:5881-5888

Karlsson S, Burman LG, Akerlund T (2008) Induction of toxins in Clostridium difficile is associated with dramatic changes of its metabolism. Microbiology 154:3430-3436

Kotowska M, Albrecht P, Szakewska H (2005) Saccharomyces boulardii in the prevention of antibiotic-associated diarrhea in children: a randomized double-blind placebocontrolled trial. Aliment Pharmacol Ther 21:583-590

Lewis S, Burmeister S, Brazier J (2005) Effect of the probiotic oligofructose on relapse of Clostridium difficile-associated diarrhea: a randomized, controlled study. Clin Gastroenterol Hepatol 3:442-448

Limaye AP, Turgeon DK, Cookson BT, Fritsche TR (2000) Pseudomembranous colitis caused by a toxin $\mathrm{A}(-) \mathrm{B}(+)$ strain of Clostridium difficile. J Clin Microbiol 38: 696-697

Lyerly DM, Krivan HC, Wilkins TD (1988) Clostridium difficile: its disease and toxins. Clin Microbiol Rev 1:1-18

Maegawa T, Karasawa T, Ohta T, Wang X, Kato H, Hayashi $\mathrm{H}$, Nakamura S (2002) Linkage between toxin production and purine biosynthesis in Clostridium difficile. J Med Microbiol 51:34-41

Mani N, Dupuy B (2001) Regulation of toxin synthesis in Clostridium difficile by an alternative RNA polymerase sigma factor. PNAS 98:5844-5849
Matsuki S, Ozaki E, Shozu M, Inoue M, Shimizu S, Yamaguchi N, Karasawa T, Yamagishi T, Nakamura S (2005) Colonization by Clostridium difficile of neonates in a hospital, and infants and children in three day-care facilities of Kanazawa, Japan. Int Microbiol 8:43-48

Medrano M, Pérez PF, Abraham AG (2008) Kefiran antagonizes cytopathic effects of Bacillus cereus extracellular factors. Int J Food Microbiol 122:1-7

Medrano M, Hamet MF, Abraham AG, Pérez PF (2009) Kefiran protects Caco-2 cells from cytopathic effects induced by Bacillus cereus infection. Antonie van Leewenhoek 96:505-513

Minnaard J, Humen M, Pérez PF (2001) Effect of Bacillus cereus exocellular factors on human intestinal epithelial cells. J Food Prot 64:1535-1541

Minnaard J, Lievin-Le Moal V, Coconnier MH, Servin AL, Pérez PF (2004) Disassembly of F-actin cytoskeleton after interaction of Bacillus cereus with fully differentiated human intestinal Caco-2 cells. Infect Immun 72:31063112

Nakamura S, Mikawa M, Tanabe N, Yamakawa K, Nishida S (1982) Effect of clindamycin on cytotoxin production by Clostridium difficile. Microbiol Immunol 26:985-992

Niers LE, Hoekstra MO, Timmerman HM, van Uden NO, de Graaf PM, Smits HH, Kimpen JL, Rijkers GT (2007) Selection of probiotic bacteria for prevention of allergic diseases: immunomodulation of neonatal dendritic cells. Clin Exp Immunol 149:344-352

Osgood DP, Wood NP, Sperry JF (1993) Nutritional aspects of cytotoxin production by Clostridium difficile. Appl Environ Microbiol 59:3985-3988

Perez PF, Minnaard J, Disalvo EA, De Antoni GL (1998) Surface properties of bifidobacterial strains of human origin. Appl Environ Microbiol 64:21-26

Plummer S, Weaver MA, Harris JC, Dee P, Hunter J (2004) Clostridium difficile pilot study: effects of probiotic supplementation on the incidence of $C$. difficile diarrhoea. Int Microbiol 7:59-62

Rönnqvist D, Forsgren-Brusk U, Husmark U, Grahn-Håkansson E (2007) Lactobacillus fermentum Ess-1 with unique growth inhibition of vulvo-vaginal candidiasis pathogens. J Med Microbiol 56:1500-1504

Ruas-Madiedo P, Gueimonde M, Margolles A, de los ReyesGavilán CG, Salminen S (2006) Exopolysaccharides produced by probiotic strains modify the adhesion of probiotics and enteropathogens to human intestinal mucus. J Food Prot 69:2011-2015

Schirmer J, Aktories K (2004) Large clostridial cytotoxins: cellular biology of Rho/Ras-glucosylating toxins. Biochim Biophys Acta 1673:66-74

Schroeder M (2005) Clostridium difficile associated diarrhea. Am Fam Physician 71:921-928

Segarra-Newnham M (2007) Probiotics for Clostridium diffcile-associated diarrhea: focus on Lactobacillus rhamnosus GG and Saccharomyces boulardii. Ann Pharmacother 41:1284-1287

Sunenshine RH, McDonald LC (2006) Clostridium difficileassociated disease: new challenges from an established pathogen. Cleve Clin J Med 73:187-197

Trejo FM, Minnaard J, Pérez PF, De Antoni GL (2006) Inhibition of Clostridium difficile growth and adhesion to 
enterocytes by Bifidobacterium supernatants. Anaerobe 12:186-193

Wullt M, Hagslatt ML, Odenholt I (2003) Lactobacillus plantarum 299v for the treatment of recurrent Clostridium difficile-associated diarrhoea: a double-blind, placebocontrolled trial. Scand J Infect Dis 35:365-367
Yamakawa K, Karasawa T, Ohta T, Hayashi H, Nakamura S (1998) Inhibition of enhanced toxin production by Clostridium difficile in biotin-limited conditions. J Med Microbiol 47:767-771 